\title{
Maternal and Child Health Services in Rural Settings of The Gambia: Contextual Determinants of Postnatal Care from Mothers' Perspectives-A Community-Based Analytical Cross-Sectional Study
}

\author{
Bakary Kinteh, ${ }^{1}$ Amadou Barrow $\mathbb{D}^{1,2}$ Musa Nget, ${ }^{1}$ Ebrima Touray, ${ }^{1}$ Jainaba Touray, \\ Sambou L. S. Kinteh, ${ }^{1}$ Mansour Badjie, ${ }^{1}$ and Solomon P. S. Jatta ${ }^{1}$ \\ ${ }^{1}$ School of Public Health, Gambia College, Brikama, Gambia \\ ${ }^{2}$ Department of Public \& Environmental Health, School of Medicine \& Allied Health Sciences, University of the Gambia, \\ Kanifing, Gambia \\ Correspondence should be addressed to Amadou Barrow; flexybams@gmail.com
}

Received 17 September 2021; Accepted 23 December 2021; Published 4 January 2022

Academic Editor: Carol J. Burns

Copyright (C) 2022 Bakary Kinteh et al. This is an open access article distributed under the Creative Commons Attribution License, which permits unrestricted use, distribution, and reproduction in any medium, provided the original work is properly cited.

\begin{abstract}
Background. Maternal and child health in The Gambia is a trending public health burden. The postnatal period is critical and vital to the lives and health of the maternal mothers and their newborns, and pieces of evidence deduced that a majority of maternal and newborn deaths occur during this period. Hence, this research aimed to assess the prevalence and determinants of postnatal care utilization across women in rural Gambia. Methods. A community-based cross-sectional design was conducted in January 2020, with 265 women of childbearing age were recruited from the selected households in rural communities across the Upper River Region (URR), Gambia, using multistage sampling technique. A structured-interview questionnaire was developed to elicit contextual sociodemographic characteristics regarding the use of postnatal care. Percentages, chi-square/Fisher's exact test for variables with $p$ value $\leq 0.15$ were considered for inclusion into the logistic regression model. The significance level was set at $p<0.05$. The adjusted odds ratios (aOR) with $95 \%$ confidence interval (CI) were computed to declare significance. Results. The study revealed that $90 \%$ of women utilize postnatal care (PNC) services in the rural settings of URR, Gambia. Factors such as women's occupation, location, number of pregnancies, attending in last pregnancy, current uptake of family planning, and complication(s) in last labor were found to be associated with PNC utilization. Women who attended antenatal care (ANC) services in their last pregnancy were 10.8 times ( $\mathrm{aOR}=10.795,95 \% \mathrm{CI}: 1.025-113.694)$, current users of FP were 10.7 times $(\mathrm{aOR}=10.708,95 \% \mathrm{CI}: 1.379-83.152)$, women's number of pregnancies increases by a factor of 4.6 times $(\mathrm{aOR}=4.649,95 \% \mathrm{CI}$ : 1.518-14.243) more likely to utilize PNC while women's number of children alive were less likely by $76.1 \%(\mathrm{aOR}=0.239,95 \% \mathrm{CI}$ : 0.071-0.810) as compared to those who were not utilizing PNC services. Conclusion. The findings showed that attending ANC services, current uptake of FP, women's number of pregnancies, and number of children alive were associated with PNC. Strengthening women empowerment and designing responsive ANC programs especially for rural women to improve PNC services are required.
\end{abstract}

\section{Background}

The postnatal period is critical and vital to the lives and health of the maternal mothers and their newborns, and pieces of evidence deduced that the majority of maternal and newborn deaths occur during this period [1]. Skilled birth attendance is critical for lowering maternal and newborn morbidities and mortalities. The World Health Organization (WHO) recommended initiating postnatal contact within 24 hours of birth and continuing with three additional interactions on day three, from week one to week two, and six weeks following birth [2]. Worldwide, around 295,000 
maternal fatalities occurred in 2017 and 2.5 million newborn deaths occurred in 2018; over 94 percent of these deaths occurred in places with limited resources $[3,4]$. The majority of these deaths might be avoided with quality services, robust programs, and interventions administered prior to and during pregnancy, all through labor and childbirth, and in the critical times after birth [5]. In developing nations, the percentage of deliveries attended by qualified healthcare staff has risen from 59 percent in 1990 to 80 percent in 2017 [4]. Each year, over a million newly born babies, die on their first day of life [6], with the majority of these deaths occurring in sub-Saharan Africa [7]. Additionally, each day, 800 women and 7700 newborns die due to problems during pregnancy and childbirth, and another 7300 women report a stillbirth in the postnatal period [5]. With a growing percentage of newborns in health facilities, those facilities see an increase in preventable maternal and perinatal mortalities and morbidities [8].

The global disparity between low- and middle-income countries as well as rural and urban areas on the deaths of newborns associated with inadequate postnatal care continued to be a significant concern and vision yet unachieved $[7,9]$. When neonates are delivered in a facility, they should receive an initial check at birth and a comprehensive clinical assessment approximately one hour following birth and before discharge [2]. The WHO's 2016 Standards for improving maternity and newborn care quality in public health systems defined the postnatal period as the six weeks following childbirth [8]. Maternal mortality rate can be improved in developing nations by investing in enabling legislation, policies, a supportive environment, extending trained personnel deliveries in rural and neglected areas, and removing financial constraints [10]. Postnatal care should contain essential components such as thermal and cord care, breastfeeding counseling, checking the baby's temperature, weighing the infant, and educating the mother on newborn danger signs [8]. Thermal and cord care are critical components of newborn care because they help maintain the infants' temperature and avert hypothermia [11]. Effective cord care is critical for preventing both mother and baby from contracting life-threatening infections [12]. PNC services are known to be among the most neglected $\mathrm{MCH}$ initiatives in Africa, as cultural norms frequently define the postpartum period. Understanding these beliefs and practices is essential for ensuring effective and timely postnatal care [13].

Maternal and child health in The Gambia is a trending public health burden. The Gambia is ranked 13th, with the highest maternal mortality rate of 597/100,000 in 2017 [14]. Moreover, a hospital-based retrospective study recorded nearly 700 maternal deaths in eight years, with an annual death rate range from over 1400 and 2100 deaths per 100,000 live births with a high burden of neonatal hospitalization $[15,16]$. To curb this high maternal death rate, the Ministry of Health developed the health policy of 2015 to 2020 to reduce the $\mathrm{MM}$ ratio from $730 / 100000$ to $150 / 100000$ by 2015 [17]. This target was far from reality as it could not be achieved, and maternal mortality is a national predicament [17]. In 2017, The Gambia Government envisaged reducing maternal and newborn mortality from 433 to 315 per 100,000 throughout the country by 2021 , as documented in the National Development Plan (NDP) 2018-2021 [18].

The multicluster survey conducted in 2018 revealed that women of childbearing age who had last live births in the last two years were 3,472 of which nearly $70 \%$ had no postnatal care [19]. As for the child's postnatal check, nearly $88 \%$ of women had their children been checked at the health center [19]. Furthermore, the national postnatal care prevalence was found to be nearly $23 \%$ and $27 \%$ for women and newborns, respectively, with marked regional variations [20]. Furthermore, the Upper River Region had more than two-thirds of her women, and newborns do not attend PNC in 2018 [20]. There is a need for a concerted effort to promote and maintain postnatal mothers' health with their newborns as the postpartum period is a critical stage.

With high maternal mortality in The Gambia, limited research is conducted on understanding the determinants of PNC within the context of $\mathrm{MCH}$ services in rural settings. Hence, this research aims to assess the determinants of PNC among women in rural Gambia. This research would inform policymakers on structural and systematic factors affecting PNC within the bigger picture of $\mathrm{MCH}$ services in rural Gambia.

\section{Methods}

2.1. Study Area. The study was carried out in the Upper River Region, the seventh and the farthest region in The Gambia. The regional administrative headquarter is located in Basse Mansajang Kunda, about $300 \mathrm{~km}$ from Banjul, the country's capital city. It has a population of more than 200, 000 persons with a population density of 115 persons per square kilometer, and it represents nearly $13 \%$ of The Gambia's population [21]. The region is administered by a Regional Governor and is further divided into seven districts such as Fulladu East, Jimara, Kantora, Sandu, Wuli East, Wuli West, and Tumana, each headed by a District Chief. Furthermore, the region is divided into the northern and southern sides by the river Gambia and has a land size of $20695 \mathrm{~km}^{2}$ [21]. The region has a district hospital, a major health center, 8 minor health centres, and 2 private clinics. URR also has a total of 17 Primary Health Care (PHC) key villages with 110 non-PHC villages. Moreover, the region has seventy-one reproductive child health outreach clinics providing reproductive, maternal, neonatal, adolescent, and child health services [22]. Conversely, URR has recorded 99.3\% antenatal visit coverage, $75 \%$ facility delivery, and PNC coverage of $18 \%$, which is low [19]. This has created a vacuum in the output of the health service delivery as postnatal care is an important indicator in maternal and newborn health. The study was carried out in January 2020.

2.2. Study Design and Population. A community-based cross-sectional study design was used to collect quantitative data from women of childbearing age. Women residing in those communities during their last pregnancy and who had a history of childbirth within the last twelve months before 
the fieldwork were included in the study. On the other side, those who were away during the last 12 months preceding the study were excluded.

2.3. Sample Size Determination and Selection of Participants. The study sample size was calculated using the Cochrane formula as shown below; a postnatal visit prevalence of $18 \%$ in the Upper River Region was adapted from the multicluster indicator survey of 2018 [19].

$$
n=p q\left(\frac{z_{\propto / 2}}{e}\right)^{2} .
$$

At 95\% confidence interval, $z$-value of alpha is $(z=1.96)$, $p$ represents the prevalence of postnatal visits from the adapted survey $(p=0.18)$, while $q$ is expressed as $1-p$ $(q=0.776), e$ represents the margin of error expressed as $(d=0.05)$, and the total sample size of $n=227$. However, the sample size was adjusted to 265 to improve the power of the study.

A multistage sampling method was used for the study; firstly, a simple random sampling (SRS) was used to select four districts (two districts from both the northern and southern parts of the region). Secondly, an SRS was used to select three villages from each, while a proportionate sampling was used to compute for each selected village. Thirdly, at the village level, the taxpayers' list was collected from the Alkalo to select households' heads randomly, and finally, participants were selected through randomization. Data collectors systematically move to the next household when the selected household has no legible participants.

2.4. Data Collection Tools. A pretested, close-ended-structured questionnaire written in English and translated into three local spoken languages: Mandinka, Fula, and Sarahule was used. Women of childbearing age were interviewed in their local language by trained research assistants from the School of Public Health, Gambia College. Data was collected through face-to-face interviews to elicited information on women's PNC uptake and sociodemographic characteristics. Participants were interviewed in their respective local languages (Fula, Mandinka, and Sarahule) by trained research assistants.

\subsection{Study Variables}

2.5.1. Outcome Variable. Postnatal care served as a dependent variable in this study. Women who had given birth within a year before the study were asked if "they have attended PNC in their last delivery." If the woman responded to have received PNC, she was coded as Yes $=1$, and if she did not receive PNC, coded as $\mathrm{No}=0$.

2.6. Explanatory Variables. A total of thirteen sociodemographic characters of reproductive-age women were considered as independent variables for this study. These included age categorized as 25 years and below, 26 to 35 years and $\geq 36$ years; marital status: unmarried/single mother, in-union/married, and divorced; educational level: no formal education, primary, secondary, tertiary, and Arabic; occupation: not working, housewife, farmer and businesswoman; family type: nuclear, extended, and single parenting; average monthly income: $<\mathrm{D} 1500(\$ 29)$ and $\geq$ D1500 (>\$29) [23]; number of pregnancies: $\leq 4$ pregnancies and $\geq 5$ pregnancies; and number of children: $\leq 3$ children and $\geq 4$ children. The respondent antenatal care attendance, place of last delivery, and complication after delivery were categorized binomially as yes or no. Lastly, the respondents' locations were geographically designated as the northern and southern parts of URR.

2.7. Data Analysis. The data were analyzed using SPSS version 25.0. A univariate analysis such as descriptive statistics was presented in frequency and percentage to identify the PNC determinants among women of reproductive age using their sociodemographic characteristics. The Pearson chi-square and/or Fisher's exact test were used to identify the association of PNC utilization with independent variables. Study variables with a $p$ value $<0.15$ at bivariate analysis level were considered for inclusion into the logistic regression model. Adjusted odds ratios (aORs) and 95\% confidence intervals were computed, while $p$ value $<0.05$ was set for declaration of statistical significance.

2.8. Ethical Consideration. An approved ethical clearance was sought from the Gambia College Research Committee (Ref. no. PH08010/2019) before proceeding with this study. Moreover, permission was also sought from the regional authorities such as the Office of the Governor, Regional Health Directorate, and the village Alkalos with their respective village development committees. At the village level, heads of households were informed of the study, and each study participant had to sign or thumbprint the consent form prior to their participation. Women were recruited voluntarily and reserved the right to stop or withdraw from the study at any stage.

\section{Results}

3.1. Sociodemographic and Related Characteristics. A total of 265 reproductive-age women were recruited for this study with a response rate of $100 \%$. About half of women were 26 to 35 years of age with a mean age of 27.5 years and standard deviation of \pm 6.0 . The majority of the women (95\%) were married, and almost half of these women had no formal education. Slightly more than one-third of these women reported being farmers. At the household level, 80\% were from the extended family system, while Mandinkas formed the majority at $78.1 \%$. A little above half of these women $(55.1 \%)$ earned less than 1500 (\$29) per month. The following variables were reported to be statistically associated with PNC service utilization: women's occupation, location, number of pregnancies, attended ANC in last pregnancy, current uptake of family planning, and had complication(s) in last labor as shown in Table 1. 
TABLE 1: Sociodemographic and related characteristics of reproductive age women in URR, Gambia.

\begin{tabular}{|c|c|c|c|c|}
\hline \multirow{2}{*}{ Variables } & \multirow{2}{*}{$n(\%)$} & \multicolumn{2}{|c|}{ Postnatal care for mother } & \multirow{2}{*}{$P$ value } \\
\hline & & No, $n(\%)$ & Yes, $n(\%)$ & \\
\hline Age of respondents & & & & 0.785 \\
\hline 25 and below & $110(41.5)$ & $11(10.0)$ & $99(90.0)$ & \\
\hline $26-35$ & $132(49.8)$ & $14(10.6)$ & $118(89.4)$ & \\
\hline 36 and above & $23(8.7)$ & $1(4.3)$ & $22(95.7)$ & \\
\hline Marital status & & & & 0.882 \\
\hline Single & $9(3.4)$ & $1(11.1)$ & $8(88.9)$ & \\
\hline Married & $251(94.7)$ & $25(10.0)$ & $226(90.0)$ & \\
\hline Divorced & $5(1.9)$ & $0(0.0)$ & $5(100.0)$ & \\
\hline Educational level & & & & 0.551 \\
\hline Nonformal education & $130(49.1)$ & $11(8.5)$ & $119(91.5)$ & \\
\hline Primary & $52(19.6)$ & $8(15.4)$ & $44(84.6)$ & \\
\hline Secondary & $40(15.1)$ & $2(5.0)$ & $38(95.0)$ & \\
\hline Tertiary & $4(1.5)$ & $1(25.0)$ & $3(75.0)$ & \\
\hline Arabic & $39(14.7)$ & $4(10.3)$ & $35(89.7)$ & \\
\hline Occupation of respondent & & & & $0.001^{*}$ \\
\hline Not working & $53(20.0)$ & $3(5.7)$ & $50(94.3)$ & \\
\hline Housewife & $91(34.3)$ & $4(4.4)$ & $87(95.6)$ & \\
\hline Farmer & $104(39.2)$ & $18(17.3)$ & $86(82.7)$ & \\
\hline Business & $17(6.4)$ & $1(5.9)$ & $16(94.1)$ & \\
\hline Family types & & & & 0.117 \\
\hline Nuclear & $46(17.4)$ & $1(2.2)$ & $45(97.8)$ & \\
\hline Extended & $212(80.0)$ & $25(11.8)$ & $187(88.2)$ & \\
\hline Single parent & $7(2.6)$ & $0(0.0)$ & $7(100.0)$ & \\
\hline Ethnicity & & & & 0.223 \\
\hline Mandinka & $207(78.1)$ & $24(11.6)$ & $183(88.4)$ & \\
\hline Fula & $43(16.2)$ & $2(4.7)$ & $41(95.3)$ & \\
\hline Serahule & $15(5.7)$ & $0(0.0)$ & $15(100.0)$ & \\
\hline Location in URR & & & & $0.049^{*}$ \\
\hline Northern region & $104(39.2)$ & $13(12.5)$ & $91(87.5)$ & \\
\hline Southern region & $161(60.8)$ & $13(8.1)$ & $148(91.9)$ & \\
\hline Average monthly income (in dalasi) & & & & 0.257 \\
\hline$<1500$ & $146(55.1)$ & $13(8.9)$ & $133(91.1)$ & \\
\hline$\geq 1500$ & $119(44.9)$ & $13(10.9)$ & $106(89.1)$ & \\
\hline Number of pregnancies & & & & $0.013^{*}$ \\
\hline 4 and below & $148(55.8)$ & $12(8.1)$ & $136(91.9)$ & \\
\hline 5 and above & $117(44.2)$ & $14(12.0)$ & $103(88.0)$ & \\
\hline Number of children alive & & & & 0.089 \\
\hline 3 and below & $174(65.7)$ & $19(10.9)$ & $155(89.1)$ & \\
\hline 4 and above & $91(34.3)$ & $7(7.7)$ & $84(92.3)$ & \\
\hline Attended ANC in last pregnancy & & & & $<0.001^{*}$ \\
\hline Yes & $260(98.1)$ & $21(8.6)$ & $224(91.4)$ & \\
\hline No & $5(1.9)$ & $5(25.0)$ & $15(75.0)$ & \\
\hline Place of last delivery & & & & 0.218 \\
\hline Home & $51(19.2)$ & $9(17.6)$ & $42(82.4)$ & \\
\hline Health facility & $214(80.8)$ & $17(7.9)$ & $197(92.1)$ & \\
\hline Currently using family planning & & & & $0.008^{*}$ \\
\hline No & $198(74.7)$ & $25(12.6)$ & $173(87.4)$ & \\
\hline Yes & $67(25.3)$ & $1(1.5)$ & $66(98.5)$ & \\
\hline Had complication(s) in last labor & & & & $0.014^{*}$ \\
\hline Yes & $123(46.4)$ & $10(8.1)$ & $113(91.9)$ & \\
\hline No & $142(53.6)$ & $16(11.3)$ & $126(88.7)$ & \\
\hline
\end{tabular}

* Statistical significance at $p<0.05$.

3.2. Postnatal Care Services and Its Determinants. The study revealed that $90 \%$ of women utilize PNC services in the rural settings of URR, The Gambia, as shown in Figure 1.
A logistic regression analysis results revealed that women's odds ratio of utilizing PNC increases by 4.6 times $(\mathrm{aOR}=4.649,95 \% \mathrm{CI}: 1.518-14.243)$ for a unit increase in 


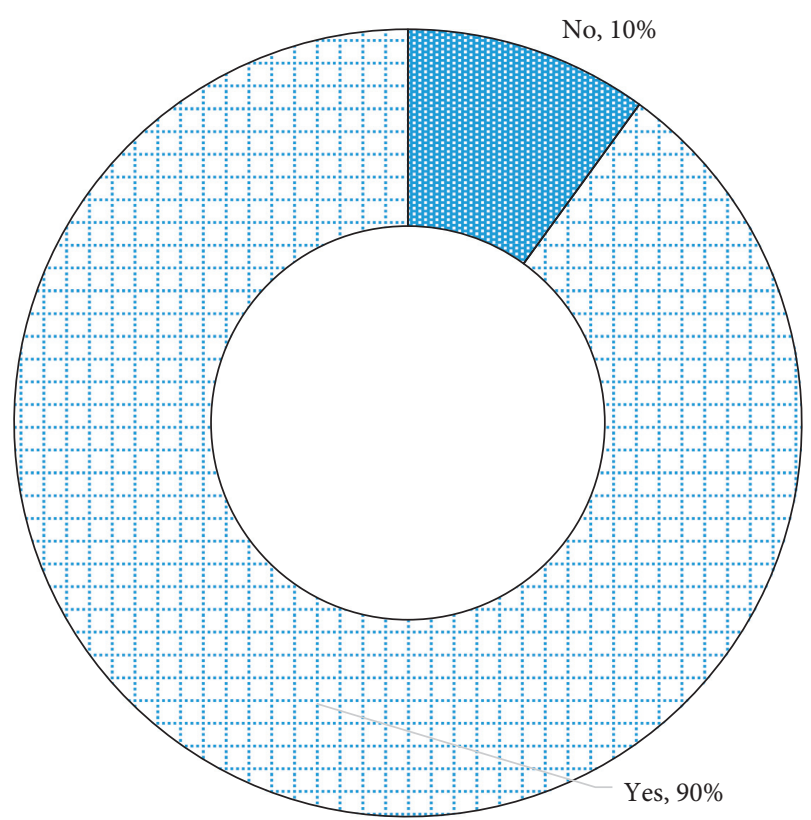

FIgURe 1: Postnatal care for mothers in URR, Gambia.

the number of pregnancies a woman has after controlling for location, ANC attendance, current use of FP, number of children alive, occupation, family types, and last complication in labor. For a unit increase in the women's number of children alive, the odds ratio of their PNC utilization decreases by $76.1 \%(\mathrm{aOR}=0.239,95 \% \mathrm{CI}: 0.071-0.810)$ after controlling for confounders: location, ANC attendance, current use of FP, number of pregnancies, occupation, family types, and last complication in labor, as shown in Table 2. Women who attended ANC services in their last pregnancy were 10.8 times $(\mathrm{aOR}=10.795,95 \% \quad \mathrm{CI}$ : 1.025-113.694) more likely to utilize PNC as compared to those who do not attend ANC in their last pregnancy after controlling for location, current use of FP, number of pregnancies, occupation, family types, children alive, and complication in last labor. Women who were currently using FP were 10.7 times $(\mathrm{aOR}=10.708,95 \% \mathrm{CI}: 1.379-83.152)$ more likely to utilize PNC compared to those who were not using FP after controlling for confounders.

\section{Discussion}

The study assessed the determinants of PNC services among women of childbearing age in rural communities of URR, Gambia. The findings from the study revealed that $90 \%$ of the respondents had attended postnatal care in their last delivery. This finding is higher than other studies including DHS 2020, MICs 2019, and [19, 20, 24]. The high prevalence of PNC among women could be attributed to the interventions of the health services through efficient and effective $\mathrm{RCH}$ services and programme intervention of Maternal and Child Health Nutrition and Reproduction Project (MCHNRP). PNC is an important indicator for both the health services and the project as financial incentives are provided for health facilities as result-based financing from the scores of their indicators.
TABLE 2: Factors associated with postnatal care for mothers in URR, Gambia.

\begin{tabular}{lcccc}
\hline & \multicolumn{5}{c}{ 95\% CI for aOR } \\
Predictors & aOR & Lower & Upper & $p$ value \\
\hline Number of pregnancies & 4.649 & 1.518 & 14.243 & $0.007^{*}$ \\
\hline Number of children alive & 0.239 & 0.071 & 0.81 & $0.022^{*}$ \\
\hline $\begin{array}{l}\text { Attended ANC in last } \\
\text { pregnancy }\end{array}$ & & & & \\
$\quad \begin{array}{l}\text { Yes } \\
\text { No (ref) }\end{array}$ & 10.795 & 1.025 & 113.694 & $0.048^{*}$ \\
$\begin{array}{l}\text { Currently using FP } \\
\quad \text { Yes }\end{array}$ & 1 & & & \\
$\quad$ No (ref) & 10.708 & 1.379 & 83.152 & $0.023^{*}$ \\
\hline
\end{tabular}

Ref $=$ reference category; $\mathrm{aOR}=$ adjusted odds ratio; $\mathrm{CI}=$ confidence in terval; and ${ }^{*}=$ statistical significance at $p<0.05$. The model was adjusted for occupation, family types, location, number of pregnancies, number children alive, attending ANC in last pregnancy, current FP uptake, and having complication in last pregnancy.

Some of the critical determinants of PNC utilization were women's ANC attendance during last pregnancy and current use of FP. This finding aligns with several studies that showed a significant association between ANC visits and PNC utilization [20, 25-27]. Traditionally, one of the most significant benefits of ANC has been the health education or counseling provided to women during their visits. This type of health education or counseling contributes to women's increased utilization of maternal health care. Women are taught good healthcare-seeking behaviors during counseling in order to reduce preventable maternal and infant death. Indeed, women who do not receive counseling or health education during their prenatal care sessions would be unaware of the relevance and benefits of PNC [28]. As a result, it is unsurprising that women who had no or few ANC visits during their previous pregnancies experienced a large decrease in PNC in rural Gambia. Improved prenatal care visits have been linked to an increased likelihood of PNC $[29,30]$. This may account for the association between PNC and previous attendance of ANC during last pregnancies.

Additionally, the study identified number of pregnancies and number of children alive to be significantly associated with PNC in the region. Women's odds of utilizing PNC increase with their number of pregnancies, which is in agreement with a study done in Ghana that indicated that $80 \%$ of women who had given birth two times attended PNC [31]. Furthermore, a study in sub-Saharan Africa has identified parity as a significant factor in PNC utilization; thus, PNC visits decrease with parity increases [26]. Individuals with more awareness are more enabled to embrace PNCs. Therefore, women with experience in pregnancies have increased tendencies of utilizing PNC services, especially in rural settings. Furthermore, we also identified that number of children alive to a woman has a reduced influence on PNC utilization. These could be attributed to structural and systemic factors, such as the attitude of healthcare workers towards maternal women, deplorable conditions of healthcare services at rural facilities, and quality of care, especially in labor and complication management. These 
findings agreed with results from previous studies $[7,20,28,32-35]$.

4.1. Strength and Limitation. This is among the few studies done in rural areas of Gambia to assess the prevalence and determinants of PNC in rural context. The exact PNC services used by reproductive-age women, infants and children, on the other hand, were not collected. Additionally, this study established merely a relationship, not causality.

\section{Conclusion}

The study showed a considerable high proportion of PNC utilization. It further identified women's attendance of ANC services, current uptake of FP, women's number of pregnancies, and number of children alive as associated factors with PNC in rural Gambia. On the basis of these results, it is advised that additional research be performed to ascertain the reasons for using or not using PNC services. Strengthening women empowerment and designing responsive ANC programs especially for rural women to improve PNC services are required.

\section{Data Availability}

The data used to support the findings of this study are available upon reasonable request from the school administration at sph@gambiacollege.edu.gm.

\section{Ethical Approval}

The study protocol was reviewed, and ethical clearance was issued by the Gambia College's Research Committee for the study (Ref. no. PH08010/2019). All methods were carried out in accordance with relevant guidelines and regulations. Before the commencement of the study, ethical approval was also obtained from URR Regional Health Directorate of the Ministry of Health and the community leaders of sampled communities.

\section{Consent}

The people were sensitized about the nature of the study in their local languages (Mandinka, Fula, Wolof, and Sarahule). Participation in the study was entirely voluntary, and only those who accepted to be part of the study were recruited. A written informed consent form was signed by each participant who accepted to be enrolled in the study.

\section{Conflicts of Interest}

The authors declare that they have no conflicts of interest regarding the publication of this paper.

\section{Authors' Contributions}

BK, AB, MN, ET, SLSK, MB, JT, and SPSJ conceptualized the study and prepared the study design. BK reviewed the literature. BK, AB, MN, ET, MB, JT, and SLSK undertook fieldwork. BK performed data input. $\mathrm{AB}, \mathrm{BK}$, and ET performed data analysis, wrote the results, discussed the findings, and wrote the initial draft of the manuscript. All authors critically reviewed the manuscript for its intellectual content. All authors read and approved the final manuscript. $\mathrm{AB}$ had the final responsibility to submit for publication.

\section{Acknowledgments}

The authors would like to extend their heartfelt appreciation to all women who took part in the study. The authors would also like to express their appreciation to the Regional Health Directorate in URR, Ministry of Health, Governor's Office in URR, youth community leaders, village heads (Alkalos), and village health workers for their assistance in mobilizing the community. Finally, the authors wish to thank students from the School of Public Health for their diligence during fieldwork and the Gambia College Administration for logistical support. This study was partly funded by the Gambia College Administration and the school alumni in a form of donations during the authors' door-to-door visits to some public and private institutions in The Gambia.

\section{References}

[1] R. A. Salam, T. Mansoor, D. Mallick, Z. S. Lassi, J. K. Das, and Z. A. Bhutta, "Essential childbirth and postnatal interventions for improved maternal and neonatal health," Reproductive Health, vol. 11, no. S1, Article ID S3, 2014.

[2] WHO, WHO Recommendations on Postnatal Care of the Mother and Newborn, World Health Organization, Geneva, Switzerland, 2013.

[3] UNICEF, "Neonatal mortality," in UNICEF DATAWorld Health Organization, Geneva, Switzerland, 2020, https://data. unicef.org/topic/child-survival/neonatal-mortality/.

[4] UNFPA, World Health Organization, UNICEF, World Bank Group, and The United Nations Population Division, Trends in Maternal Mortality 2000 to 2017: Estimates by WHO, UNICEF, UNFPA, World Bank Group and the United Nations Population Division, World Health Organization, Geneva, Switzerland, 2019.

[5] WHO, Making Every Baby Count: Audit and Review of Stillbirths and Neonatal Deaths, World Health Organization, Geneva, Switzerland, 2016.

[6] A. Singh, S. S. Padmadas, U. S. Mishra, S. Pallikadavath, F. A. Johnson, and Z. Matthews, "Socio-economic inequalities in the use of postnatal care in India," PLoS One, vol. 7, no. 5, Article ID e37037, 2012.

[7] N. D. Lam, N. D. Anh, N. T. T. Ha, T. Q. Vinh, V. T. M. Anh, and V. D. Kien, "Socioeconomic inequalities in post-natal health checks for the newborn in Vietnam," International Journal for Equity in Health, vol. 18, no. 1, Article ID 128, 2019.

[8] WHO, Standards for Improving Quality of Maternal and Newborn Care in Health Facilities, World Health Organization, Geneva, Switzerland, 2016.

[9] A. Probandari, A. Arcita, K. Kothijah, and E. P. Pamungkasari, "Barriers to utilization of postnatal care at village level in Klaten district, central Java Province, Indonesia," BMC Health Services Research, vol. 17, no. 1, Article ID 541, 2017. 
[10] I. Pathmanathan, J. Liljestrand, J. Martins, L. Rajapaksa, C. Lissner, and A. de Silva, Investing in Maternal Health: Learning from Malaysia and Sri Lanka, World Bank, Washington, DC, USA, 2003.

[11] K. Lunze and D. H. Hamer, "Thermal protection of the newborn in resource-limited environments," Journal of Perinatology, vol. 32, no. 5, pp. 317-324, 2012.

[12] H. T. Tran, P. Mannava, J. C. S. Murray et al., "Early essential newborn care is associated with reduced adverse neonatal outcomes in a tertiary hospital in Da Nang, Viet Nam: a prepost- intervention study," EClinicalMedicine, vol. 6, pp. 51-58, 2018.

[13] C. Warren, P. Daly, L. Toure, and P. Mongi, Opportunities for Africa's Newborns, WHO on behalf of The Partnership for Maternal, Newborn and Child Health, Geneva, Switzerland, 2016.

[14] CIA World Factbook, "Maternal mortality rate-country comparison," 2019, https://www.indexmundi.com/g/r.aspx? $\mathrm{c}=\mathrm{ga} \& \mathrm{v}=2223$.

[15] B. Camara, C. Oluwalana, R. Miyahara et al., "Stillbirths, neonatal morbidity, and mortality in health-facility deliveries in urban Gambia," Frontiers in Pediatrics, vol. 9, p. 579922, Article ID 579922, 2021.

[16] P. Idoko, M. O. Anyanwu, and S. Bass, "A retrospective analysis of trends in maternal mortality in a Gambian tertiary health centre," BMC Research Notes, vol. 10, no. 1, Article ID 493, 2017.

[17] Ministry of Health and Social Welfare, National Health Policy 2012-2020, Ministry of Health and Social Welfare, Banjul, Gambia, 2012.

[18] Gambia Government, "The Gambia national development plan (2018-2021)," pp. 90-95, Ministry of Finance and Economic Affairs, Banjul, The Gambia, 2017.

[19] The Gambia Bureau of Statistics, The Gambia Multiple Indicator Cluster Survey 2018, UNICEF, Geneva. Switzerland, 2019.

[20] A. Barrow and A. Jobe, "Predictors of postnatal care service utilization among women of childbearing age in the Gambia: analysis of multiple indicators cluster survey," International Journal of Women's Health, vol. 12, pp. 709-718, 2020.

[21] GBoS, Distribution of Population by Gender and LGa, Gambia Bureau of Statistics, Serekunda, Gambia, 2013.

[22] GBoS, "Gambia bureau of statistics health statistics of Gambia, 2020-Gambia data portal," GBoS, Serrekunda, The Gambia, 2020.

[23] Dollar to Gambian Dalasi, "Dollar to Gambian dalasi exchange rate today, live 1 USD to GMD $=51.1606$ (convert dollars to Gambian dalasi)," 2021, https://www.exchangerates. org.uk/Dollars-to-Gambian-Dalasi-currency-conversionpage.html.

[24] GBoS, "The Gambia bureau of statistics (GBoS), Ministry of health (MoH) [the Gambia], and ICF. 2020," The Gambia Demographic and Health Survey 2019-20: Key Indicators Report, The Gambia Bureau of Statistics, Ministry of Health, and ICF, Banjul, The Gambia and Rockville, MD, USA, 2020.

[25] T. L. Abota and N. TadeleAtenafu, "Postnatal care utilization and associated factors among married women in Benchi-Maji zone, southwest Ethiopia: a community based cross-sectional study," Ethiopian Journal of Health Sciences, vol. 28, no. 3, Article ID 267, 2018.

[26] L. Benova, O. Owolabi, E. Radovich et al., "Provision of postpartum care to women giving birth in health facilities in sub-Saharan Africa: a cross-sectional study using
Demographic and Health Survey data from 33 countries," PLoS Medicine, vol. 16, no. 10, Article ID e1002943, 2019.

[27] S. Yaya, O. A. Uthman, A. Amouzou, M. Ekholuenetale, and M. Bishwajit, "Inequalities in maternal health care utilization in Benin: a population based cross-sectional study," BMC Pregnancy and Childbirth, vol. 18, no. 1, Article ID 194, 2018.

[28] M. A. Limenih, Z. M. Endale, and B. A. Dachew, "Postnatal care service utilization and associated factors among women who gave birth in the last 12 Months prior to the study in Debre Markos town, northwestern Ethiopia: a communitybased cross-sectional study," International Journal of Reproductive Medicine, vol. 2016, no. 3, 7 pages, Article ID 7095352, 2016.

[29] T. Abuka Abebo and D. Jember Tesfaye, "Postnatal care utilization and associated factors among women of reproductive age Group in Halaba Kulito Town, Southern Ethiopia," Archives of Public Health, vol. 76, no. 1, Article ID 9, 2018.

[30] B. B. Bwalya, M. C. Mulenga, and J. N. Mulenga, "Factors associated with postnatal care for newborns in Zambia: analysis of the 2013-14 Zambia demographic and health survey," BMC Pregnancy and Childbirth, vol. 17, no. 1, 2017.

[31] F. Appiah, T. Salihu, J. O. D. Fenteng et al., "Postnatal care utilisation among women in rural Ghana: analysis of 2014 Ghana demographic and health survey," BMC Pregnancy and Childbirth, vol. 21, no. 1, Article ID 26, 2021.

[32] D. J. Damian, J. Y. Tibelerwa, B. John, R. Philemon, M. J. Mahande, and S. E. Msuya, "Factors influencing utilization of skilled birth attendant during childbirth in the Southern highlands, Tanzania: a multilevel analysis," BMC Pregnancy and Childbirth, vol. 20, no. 1, Article ID 420, 2020.

[33] E. E. Chaka, A. A. Abdurahman, S. Nedjat, and R. Majdzadeh, "Utilization and determinants of postnatal care services in Ethiopia: a systematic review and meta-analysis," Ethiopian Journal of Health Sciences, vol. 29, no. 1, 1970.

[34] B. N. Rwabufigiri, J. Mukamurigo, D. R. Thomson, B. L. HedtGautier, and J. P. S. Semasaka, "Factors associated with postnatal care utilisation in Rwanda: a secondary analysis of 2010 Demographic and Health Survey data," BMC Pregnancy and Childbirth, vol. 16, no. 1, Article ID 122, 2016.

[35] K. G. Wudineh, A. A. Nigusie, S. S. Gesese, A. A. Tesu, and F. Y. Beyene, "Postnatal care service utilization and associated factors among women who gave birth in Debretabour town, North West Ethiopia: a community- based cross-sectional study," BMC Pregnancy and Childbirth, vol. 18, no. 1, Article ID 508, 2018. 